\title{
TECHNICAL ANALYSIS OF REMOTE 3D Visualization ON MOBILE DEVICES
}

\author{
Ms. U. S. Junghare ${ }^{1}$, Dr. V. M. Thakare ${ }^{2}$, Dr. R. V. Dharaskar³, \\ Dr. S. S. Sherekar ${ }^{4}$ \\ ${ }^{1}$ Brijlal Biyani Science College, Amravati, MS. India. \\ us junghare@yahoo.co.in \\ ${ }^{2,4}$ SGB Amravati University, Amravati, MS. India. \\ vilthakare@yahoo.co.in \\ s._sherekarerediffmail.com \\ ${ }^{3}$ M.P.G.I. Nanded, MS. India. \\ rvdharaskarerediffmail.com
}

\begin{abstract}
Considering the limitations of mobile devices like low bandwidth, less computation power, minimum storage capacity etc it is not possible to store whole data for $3 D$ visualization on mobile devices. Therefore to minimize the load of mobile devices there is use of server in case of remote $3 D$ visualization on mobile devices (clients). For 3D visualization on mobile devices various techniques are used at server side as well as at mobile side for different purpose. Some techniques directly provides 3D visualization and some techniques are indirectly responsible for $3 D$ visualization on mobile devices. Remote visualization on mobile devices includes various parameters and aspects in different techniques.
\end{abstract}

\section{KEYWORDS}

Client, server, remote visualization, mobile devices

\section{INTRODUCTION}

Remote 3D visualization is used in wide areas such as complex urban environments, navigation, illustration, education such as for Cultural Heritage and rendering of large cities etc. As the mobile devices have so many limitations therefore 3D visualization of such wide area on mobile is a tedious task. This tedious task is made easier by server by providing various facilities with the help of various techniques at server side. Techniques are used at remote side (server) such as data compression, preprocessing, asynchronous adaptation etc and then pictures has been transferred to mobile devices for 3D visualization via wireless network. As it is a concept of wireless network, remote communication etc therefore it includes various aspects such as transmission delay, bandwidth, frame rates, catch, throughputs etc.

\section{AREAS FOR REMOTE 3D VISUALIZATION ON MOBILE DEVICES}

3D remote visualization is useful for earth maps or small patch of geographic area on mobile devices [1]. 3D remote visualization for scenery features of cities such as terrain, building, road etc [2]. 3D visualization of complex stream based data like video games etc. and visualization of $3 \mathrm{D}$ models like vehicle at remote side $[3,5]$. The main goal is to access ambient intelligent environment by implementing, and evaluating a 3D-based user interface. Previously there were so many problems like interaction with small devices without there own user interfaces, finding and accessing devices in an invisible and unfamiliar environment etc. So with the help of 3D visualization and 3D UI a logical link has been created between physical devices and performs virtual representation on mobile devices [6]. To perform 3D visualization on mobile devices of outdoor environment GPS tracing system is used. This system may use with 2D visualization but it gives very poor sight as compare to 3D. Here authors focus on 3D visualization for real time indoor location tracing system on mobile devices [7]. Software architecture is capable to

DOI : $10.5121 /$ ijcsit.2011.3608 
support the execution of agent-based participatory simulation activities and to provide them in a 3D virtual environment on mobile devices. Simulation and agent based modeling are the scientific methodology. This is also known as Agent Based Modeling Simulation (ABMS) technology. The main part of this system is to represent visual simulation using 3D visualization engine on mobile devices [8]. The main objective is to view $3 \mathrm{D}$ virtual reality data on mobile devices. Today's mobiles are more powerful however there is a need to reduce the content and need of processing data. Here Markus Feibt and Andreas Christ concentrate on most famous technology data compression. To achieve this, data has been first pre process at server side. As the mobiles which are at client side have so many limitations so to display 3D virtual reality data, concentration is only on device specific properties. To provide 3D virtual reality there is use of VRML. As the wireless connection via wireless network is not more reliable due to their limited bandwidth therefore 3D virtual reality has been optimized before going towards wireless network [9]. Here the focus is on remote 3D visualization of large cities using expressive or non-photorealistic rendering (NPR). To perform such rendering client server system and preprocessing optimization technique has been introduced. Here buildings are considered as simple texture blocks which are photographs of real building frontage. It also implements pipelines from real building frontage in prototype system which has been sent to remote clients [10]. As the mobile devices have so many limitations therefore 3D rendering on mobile is a challenging task because it requires huge network band width and computing resources. To solve this problem there is use of real time remote rendering of $3 \mathrm{D}$ video with the help of proxy based structure. Proxy server performs the rendering of complete 3D video and then transfers the render picture on mobile via wireless network [11]. It is possible to visualize image data at client side from server at remote side. Server is a web server which provides images to client on its demand [12].

By considering the limitations of mobile devices Fabrizio, Lamberty and Andrea Sanna provides the remote computing technique for the visualization on mobile devices [13]. It generates GUI events and transmits it to mobile applications.

City map visualization is possible through wireless network and GPS. It is also possible to create real time rendered mobile virtual environment with direct one to one mapping as 3D [14]. It also provides 3D optimization with dynamic entity.

A system has been developed which provides information about location to users and also navigate though mobile images [15]. The focus is on indoor environment. System uses client server approach for the location and direction in indoor environment.

Here [16] provide system which provides on line and offline data visualization for tourist in the tourist region. This system put together satellite images, GPS data, GIS and other information. All this information is used to implement visualization on mobile devices. This tourism information system handles large information which then used to provide guidance of desired destination.

Scalable processing provides in [19] for moving location query as location tracking request. It monitors the location of mobile object using optimization technique and this approach is MobiEyes. Direct benefit of MobiEyes is to reduce server load and communication band width. Various optimization techniques are used to reduce the computation at mobile side.

To visualize complex virtual 3D scenes and navigate those on mobile devices a novel approach is proposed. This approach is based on geographic web services. Client-server approach is also proposed in which servers dynamically generate the 3D scenes in provisions of the navigation commands and the result is sent to the mobile client like video-encoded image stream [20].

Generally a mobile device has limited hardware so it's difficult to create high constancy graphics in realistic time. Therefore to minimize this time there is used of remote server along 
with mobile device to render high constancy graphics. Here client server framework has been used to reduce rendering time using cost function [22].

A system is proposed by [23] having controller which automatically controls streaming parameters and increases quality of service in remote visualization. This is possible after designing control algorithm. While designing controller it is necessary to have sensitivity to feedback measures, robustness to non-linearity, freedom to the network quality and best handling of available resources.

A general architecture is developed for the visualization and navigation through 3D views on mobile devices by developing 3D museum applications. By means of which various mobile clients can interact with each others [24].

Gianluca Paravati et al. focus on Quality of Experience aspect in remote visualization on mobile device. Even the remote visualization through network provides quality of service but if it doesn't satisfy users then there is not quality of experience [26].

Here in [27] focus is on visualization of medical data on thin mobile client device by means of grid computing. This allows the mobile client to interact flexibly in grid environment.

\section{IMPORTANT ISSUES TO BE CONSIDERED FOR REMOTE AND MOBILE SIDE FOR 3D VISUALIZATION ON MOBILE DEVICES}

Following are the important issues to be considered for the remote 3D visualization on mobile devices:

1. Roaming step length control, motion blur, and triangle strips division

2. TIN-based vertex generation method

3. Cluster based rendering

4. Interactive generic algorithm

5. Ambient control and The Dynamic User Interface Creator

6. Culling algorithm and RSSI (received signal strength indicator) algorithm

7. Agent Based Modeling Simulation (ABMS) Technology

8. Data compression algorithm and dynamic optimization technique

9. Non-photorealistic rendering (NPR) and preprocessing optimization technique

10. Image based approach with 3D wrapping technique

11. Image Tilling, Multi-resolution Streaming, zoom and rotation

12. GUI with Segmentation, Optical character recognition and Pattern matching techniques

13. Image Segmentation and Matching technique

14. 3D Multimedia Visualization with interactive navigation

15. Multi-resolution, view frustum culling, occlusion culling, imposter techniques, and scenegraph optimizations

16. Adoptive and model view Control System

17. Volume and Iso-surface rendering methods

Remote concept plays an important role for 3D visualization on mobile devices. It makes complex data visualization easier because it supports client server approach having wireless connection. There is no limit of distance between mobile client and server. To visualize complex data from remote side on mobile devices includes various methods, parameters and aspects. Remote visualization on mobile devices is used in different applications for different types of complex data like earth maps, geographic area [1], terrain building, road [2], video games [3,5], ambient intelligent environment [6], 3D virtual reality data [9], outdoor and indoor environment [15], tourist region [16], medical data [27], 3D museum applications [24] etc. As the mobile devices doesn't have so much memory or storage capacity, therefore this complex data comes from server side to visualize on mobile clients with help of some methods at server side and client side. 
International Journal of Computer Science \& Information Technology (IJCSIT) Vol 3, No 6, Dec 2011

\section{Server Side Methodologies}

\subsection{Roaming step length control, motion blur, and triangle strips division, data scheduling}

There are different techniques to improve the efficiency of 3D rendering with smooth roaming function in $3 \mathrm{D}$ environment, on the intelligent mobile devices. This rendering occurs through wireless data transmission. Different techniques to improve the 3D rendering are roaming step length control, motion blur, and triangle strips division. Roaming step length means minimized change of view. To achieve this view, in roaming step length control the rendering process would not be executed until the actions of operations have exceeded the limit. It has been found that roaming step length of operations directly reflects the correctness of user's operations.

It is clear that when the roaming step length is short, the globe would rotate accurately, and if the step length is long, the globe would rotate in a rough manner. Dynamic adjustment rules are set for the smoothness of real-time operation and to reduce the actual frequency of rendering.

Motion blur is used to improve the system rendering speed i.e. when the small patch of geographic picture is render in the procedure of dynamic roaming operation it extract the reduced pictures. To reduce the 3D representation time there is division of landscape meshes of each patch into triangle strips [1].

To manage data on wireless network data scheduling is also required.

\subsection{Cluster based rendering}

The focus is on remote visualization in $[3,4]$ and for that three tired architecture is proposed. In this architecture clients or mobile devices has been connected to the remote visualization server (RVS) which manages the communication between the 3D graphics application in a distributed environment. Also the visualization interface is organized on mobile devices. OPENGL applications are also used at server side whose callback functions adjust the rendering and mapping parameters. Also the cluster based rendering subsystem has been organized using Chromium which follows client-server paradigm by which OPENGL directives are intercepted. One s/w module is implemented i.e. SPU (steam processing unit) as a dynamically loadable library. It supports graphics context subdivision in tiles, distributing computing workloads to cluster nodes, performing actual rendering, returning the result to Chromium clients, and reassembling image tiles.

\subsection{Interactive generic algorithm and controller}

In [5], interactive generic algorithm has been produced to improve the performance which allows high quality graphics contents on site by linking set of 3D model. This system also allows user to design 3D graphics content on mobile devices for real time visualization. As the mobile device has less computing power for real time visualization so it provides client server architecture to manage computing load.

In interactive generic algorithm the numbers of steps are creation of initial generation, find out optimum solution, check the model and specify rates, execution of GA operation to produce new pair of models and last step is the visualization of new models as shown in fig. 1. Server side also includes controller to manage interaction with user. 


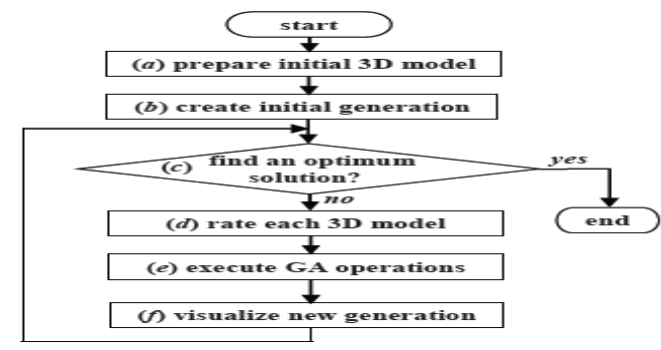

Fig. 1: Flowchart of iGA-Based 3D modeling.

\subsection{Ambient control and The Dynamic User Interface Creator}

Ambient control (AMCo) is implemented which uses automatic created 3D visualization model of environment and also built integrated user interface at server side. This identifies new devices and also can access identified devices. AMCo also have windows icon menu and pointing to access video, music, slides documents and also provides drag and drop facility. On a mobile device the Interaction Appliance (IA) runs, this makes available the AMCO client and the user interface. The Dynamic User Interface Creator (DUIC) has been implemented as a built-in component of the Environment Manager for the dynamic 3D-Visualization. Environment manager has so many functions like device access, dynamic user interface creation, and context retrieval, interaction synchronization etc. In case of DUIC environment manager illustrate the current position of environment with the help of XML file in 3D user interface. Interaction synchronization manages simultaneous access to the current environment [6].

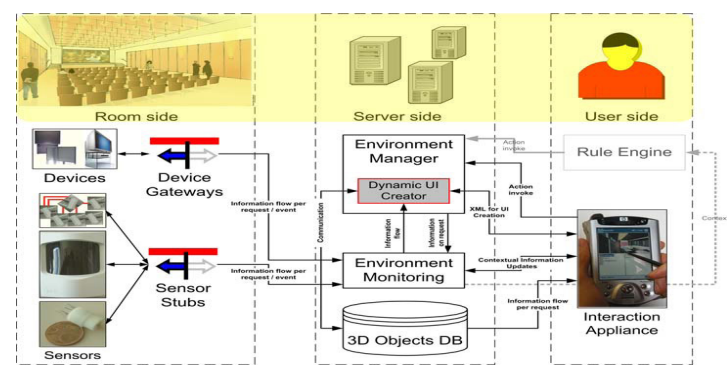

Fig. 2: The system runs on several distributed machines and subsystems.

\subsection{Agent Based Modeling Simulation (ABMS) Technology}

In system architecture of ABMS consist of Request manager, state updater, and snapshot creator at server side. In this system initially users from there system issues set of orders to the set of organized agents. This order is taken by Agent manager which is further send to Request manager. After that there is state updater, who creates new states, Snapshot Creator makes a text based image for the newly created state. This is all carry out on wireless network and this is all done under ABMS platform. Main goal of [8] is to provide 3D visualization using visual engine on wireless devices.

\subsection{Data compression algorithm and dynamic optimization technique}

Optimization of $3 \mathrm{D}$ virtual reality data is done by two ways i.e. static and dynamic optimization. In static optimization conditions are not changed during execution. In case of static optimization data compression is either done by software or hardware to reduce data transmission rate. Hardware compression algorithm may use for software compression but it never change for different types of clients. In other case software compression algorithm may used for lower clients to use a lower compression rate as well as powerful devices for higher and more data compression. If preload and catching technique is used at client sides then it 
requires clients with more storage capacity. So to avoid this problem same techniques are used at server (VRML proxy) side. When clients wants to connect to server they have to infer to server about device capacity, processing power, sound resolution etc then server removes unwanted contents according to the client i.e. mobile device requirement.

In case of dynamic optimization, incremental data transmission is used which transfer only minimum needed data. Data processing is done at VRML proxy server side rather than client side.

For VRML proxy there is use of java programming language.

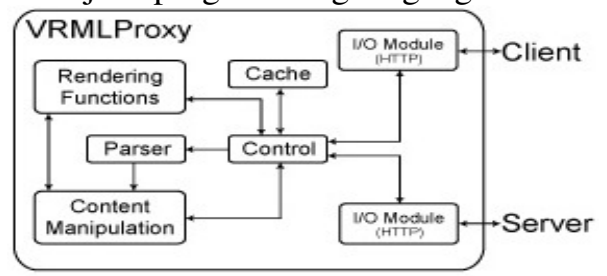

Fig 3: VRML Proxy view.

Here I/O module provides communication between client and server shown in fig.3. Content manipulation reduces the unwanted contents to mobile [9].

Common optimization provides static view while the dynamic optimization provides real time rendering of dynamic entities. Culling algorithm is also used to manage dynamic entities by initially deleting them and then adding them into new position. To ensure the scalability of system take out positioning information from client and due to parallel conflicting there is no need to validate client states at server side. Server manages entities by registering subscription. Dynamic entity updates are distributed by fast entities servers using entity proxies $[14,18]$.

Pietro Zanuttigh et al [21, 31, 32, 38] provide predictive compression method for the visualization of 3D model at remote side. This method reduces the download time and control the flow of 3D data. Main goal of predictive schema is to compress and transmit prediction error. For the compression of transmitted data it is necessary to packed scatter pixels of data in an array. Author presents various algorithms for the remote visualization of 3D models.

Matt Aranha et al. [22] discuss technique which minimizes computation and time for the rendering of more graphics on mobile devices. Ray tracing is one of the techniques which doesn't need more pixel as compare to desktop. As it uses client server concept so first it establish the communication between client and server using TCP/IP, then data has been compress at server side to reduce amount of transmitted data and decompress at client side. It also uses cost function to reduce rendering time of pixel on mobile device.

Robert Sisneros et al. [25] developed architecture having two aspects caching and pre-fetching for remote visualization. Caching aspect uses adoptive optimization technique for remote visualization to minimize average fetch time.

QoE is related to user observation in remote visualization on mobile devices through network. Actually QoE can move towards applications without network structure. Here in [26] focus is on QoE in remote visualization so it relates to the parameters frame rates, image resolution, compression quality and bandwidth.

Here authors [27] propose visualization pipeline having various components. One of the components is data service to bring and send data, other is filter service to receive data from data service and it uses data compression method to reduce size of data file.

To visualize and manipulate remote large data in real time on mobile devices M. Panka et al. [28] proposed a remote interactive visualization on mobile devices with the help of distributed system. All data are rendered on given servers of this system and compress while transmission 
using video codec. This compress data is send to mobile client as single video stream of good quality with high frame rates.

Pradeep Sen et al. perform ray tracing rendering to utilize wavelet based final image using compression algorithm. But in low sampling density compressive rendering fails [37].

\subsection{Non-photorealistic rendering (NPR) and preprocessing optimization technique}

The very first part of this system is to perform modeling and optimization of 3D representation of texture blocks of real building frontage. Pipe lines are extracted from real building frontage using edge detector. In case of edge detector image is smoothen by Gaussian convolution and also calculate gradient with the help of kernels and then obtain a pixel which is very well superiority of line extraction. To obtain poly lines, pixel chain has been obtained by finding pixel neighbors. To find polygonal approximation each pixel has been process which is vectorization process. To correct the errors occurs due to vectorization and initial noise there are different steps like suppression of segments, junction merging, straight line detector, vertical and horizontal line fittings. After vectorization last process is rendering process. In rendering process lines of real building frontage has been used as image. There is also another way in which lines are represented by geometric primitive on the surface of building. It has been found that texture rendering is faster than image rendering. This technique uses client server approach in which render data has been store on server such data then optimize for remote visualization on client like mobile device, PDA etc. Optimization technique has been used due to the fewer configurations of clients [10].

MobiEyes system is divided into two parts i.e. server side processing and client side processing. In server side processing server stores information of mobile object in focal object table, data of spatial queries in moving query table. Also the reserve query index matrix stores the identifier of the queries and static grid cell to base station mapping. Client (mobile) side stores the local query table having data about moving query and Boolean variable. Server side processing handles moving location query installation request from mobile side and make mediation at both side. Mobile side processing checks whether mobile object is within monitoring area of the moving query and query's filter is satisfied or not. If both answers are true then it registers the query into local query table. Author provides several optimization techniques for efficient and reliable processing of moving query. Those are lazy query propagation, query grouping and safe period which reduce the processing load at mobile side and also reduce the messaging cost of whole system [19].

\subsection{Image based approach with 3D wrapping technique}

By considering the limits of mobile devices, author presents the proxy based structure for remote rendering on mobile. Here proxy is a powerful server on which whole $3 \mathrm{D}$ video is available and then it sends render pictures on mobile device (client) according to there request. Proxy contents different modules like rendering module, motion module, output and input stream interface. Gateway server communicates with input stream interface and send 3D video stream to proxy. User interface is managed by motion module. Client i.e. mobile device receive image from output stream interface of proxy and display it. When the client requests for new rendering then interaction delay may occur due to network traffic. This interaction delay is reduced with the help of image based approach.

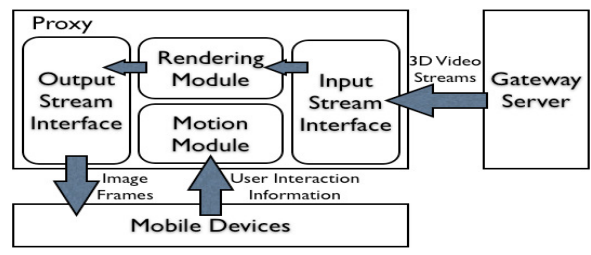

Fig 4: proxy based framework. 
Image based approach uses 3D wrapping technique to reduce interaction delay. 3D wrapping algorithm needs camera parameters and pixel depth value. In case of OPENGL the camera parameters receive from model view and projection matrix, and the pixel depth values are stored in z-buffer. Wrapping is computed by following formula,

$$
\left(u_{2}, v_{2}\right)=\left(\frac{u_{1} a+v_{1} b+c+\partial_{1} d}{u_{1}+v_{1} j+k+\partial_{1} l}, \frac{u_{1} e+v_{1} f+g+\partial_{1} h}{u_{1} i+v_{1} j+k+\partial_{1} l}\right)
$$

In this algorithm next coordinates $\left(\mathrm{u}_{2}, \mathrm{v} 2\right)$ are calculated from the input pixel of its previous coordinate's $\mathrm{u}_{1}, \mathrm{v}_{1}$. It also uses depth value of pixel $\mathrm{u}_{1}, \mathrm{v}_{1}$. This algorithm computes each pixel only once. Therefore the complexity of the whole algorithm is proportional to the image resolution. Input image has no pixel to reference when drawing new image, such problem is exposure problem. This problem is overcome by selecting two reference image frames and 3D wrapping is used for both frames [11].

In [36] Sylvain Faisan et al. proposed 3D binary image warping technique in accordance with continuous and one to one mapping. Warping is nothing but an image transformation process, in which warping image $\mathrm{M}$ can transform to image $\mathrm{T}$ by means of two ways, considering each point of $\mathrm{M}$ whose coordinates in $\mathrm{T}$ and other considering each point of $\mathrm{T}$ and whose coordinates in $\mathrm{M}$. It is time consuming and expensive.

\subsection{Image Tilling, Multi-resolution Streaming}

Photographs or images are accepted by system as input. These images are preprocessed by an encoder to produce new subdivided (tile) multi resolution images. All streaming and encoding information is store into map and catalog files produce by encoder [12]. This is done at server side.

\subsection{GUI with Segmentation, Optical character recognition and Pattern matching techniques}

Fabrizio Lamberty et al. [13] provide client server frame work. Server side provides GUI to the mobile devices with four elements. Those are parser, classifier and descriptor. Parser examines the interfacing. Classifier categorizes each element to place them together. Descriptor is used to convert each information into user interface description language, which holds entire interface description and GUI brokers connects to mobile to access the request and send the parses description to mobile to present to user. Each GUI uses some techniques for various purposes. GUI parser uses frame buffer for interfacing with user, ad hoc algorithm to interact with OS. GUI classifier uses segmentation to segment image onto sub blocks, optical character recognition to recognize text in bounding box and the pattern matching technique to checks character shapes and attributes. XML user interface is used by GUI descriptor which is helpful for remote interfacing.

\subsection{Image Segmentation and Matching technique}

To provide location and positioning in indoor environment along with information, a system $[15,18]$ has been developed on the basis of client server approach. In this system sends the images to server using wireless signals. Server extract applicable feature in the images to match to base plane. These feature detect method is based on image segmentation which finds segment by selecting search area and lines trace. After finding feature it should match with floor plane so the matching is occur using Ransac algorithm in which one to one correspondence is occur between left and right side of floor plane and image feature. Then it computes camera pose and send information overlay to mobile client to visualize indoor location. Here all techniques are used at server side. 
International Journal of Computer Science \& Information Technology (IJCSIT) Vol 3, No 6, Dec 2011

\subsection{Multi-resolution, view frustum culling, occlusion culling, imposter techniques, and scene-graph optimizations}

To perform 3D visualization of complex virtual environment on mobile devices there are different visualization techniques, including discrete and continuous multi-resolution geometry and texture representations, progressive and hierarchical representation with client-server architecture, view frustum culling, occlusion culling, imposter techniques, and scene-graph optimizations. But 3D navigation applications go through short of data values and flexible distribution techniques. So the data can only be used for visualization purpose but not for higher-level functionality such as simulations, analysis tasks etc.

This application uses general techniques those are Quad-tree, BSP (Binary Space Partitioning) tree and Octree to divide and arrange data with multi-resolution by means of pyramid mode into hierarchical structure. It also uses mipmap texture for higher resolution, interpolation between original source images [20].

\subsection{Adoptive and model view Control System}

Control system considers the theoretical bandwidth occupation, device throughputs. Bandwidth error considers the increase between visualization flow created by server and the flow process by mobile client. Throughput is depends on both network and mobile capabilities. If the throughput is lower than bandwidth then it means that mobile is not capable to receive, decode and visualize all flow sent by server. Therefore controller is implemented at server side which decreases the encoding parameters to reduce the wasting of bandwidth. Target frame rate is also used for the external control of parameters. So the target frame rate is always comparing with actual frame rate of client and the controller always tried to reduce this difference. Controller also changes the parameters of the flow of images to reach the preferred frame rate to use minimum bandwidth of network and client processing capability. To manage the instability of bandwidth and device throughput the adoptive control approach can be used. The optimization technique is used with proposed controller to rearrange the resolution, frame rate and quality that are mentioned in [33]. In overall simulation initially target frame rates was $15 \mathrm{fps}$ in time $\mathrm{t} 1$ after that it becomes 25 in time $\mathrm{t} 2$. To get a higher frame rates even though resolution and quality decreases but it doesn't provides stable value due to nonstop fluctuation [23].

The developed architecture is based on Model View Controller which consist of views like local and remote, device controller and M3G. M3G controls data and performance of the 3D graphical object. M3G model also check and responds on the collision of graphical objects. Graphics are mapped on device display with help of local and remote views. Remote view is responsible to render on remote mobile devices. Device controller act as interpreter between mobile devices and $3 \mathrm{G}$ model so that device users can interact with applications. Communication layer acts as data communicator with server. Once the connection is established server receive images from other devices in the ad hoc network and sends it to current mobile device. Therefore navigation and interaction is occurs in between multiple mobile clients. Author [24] developed architecture to deal with fault tolerant aspect. This architecture is tolerant to failure to communicate with server by allowing 3D scene to be loaded from nearer device.

For the optimal decomposition and adoptive mapping of visualization pipeline over distributed network Mengxia Zhu et al. proposes various aspects of remote visualization system. Visualization pipeline is developed to reduce the total delay and to increase frame rates because this pipeline is arranged into group of modules which is allocated to various network nodes. While in distributed visualization system visualization pipeline is decomposed into groups and then mapping is occurs in between these groups and computing nodes distributed over transport network $[29,30]$. 
Here in [34] the discussion is on integration of two techniques i.e. web content adaptation and dynamic content catching. To display dynamic content on mobile devices content adaptation is employed which uses page adaptation method. Content adaptation helps for dynamic visualization and catching increases speed of content transmission. The proposed adaptation algorithm is modified by consisting of two parts semantic block detection and semantic block partition. Enhance fragment catching strategy increase the dynamic content adaptation and it solve both transmission and adaptation cost.

When the visualization on mobile is performed through wireless network from remote side, a lot of problems may occurs relates to data transmission, bandwidth, frame rates etc. like these energy utilization may also be the problem. Therefore adoptive synchronization method is proposed in [35] which solve the problem of energy consumption and increase transmission speed.

Milos Bogdanovic et al. proposes context service architecture for adoptive geospatial data visualization. Detail visualization of spatial data on mobile through web is a time consuming task [39].

\subsection{Volume and Iso-surface rendering methods}

Aboamama .A. Ahmed et al. propose visualization pipeline with various components. With the help of this it is possible for the mobile client to interact in distributed network environment. Visualization pipe line contains various components such data service to bring and send data, filter service to receive data from data service. It also use data compression method to reduce size of data file, mapping service converts the data in geometric format using volume and isosurface rendering methods. Render service render the geometric data into image to transfer towards visualization agent via presentation service. Render service acts on network bandwidth to receive request from visualization agent which is implemented in Java 3D and xml [27].

\section{Client Side Methodologies}

\subsection{Asynchronous adaptation, progressive refreshment, roaming, rendering}

To release the burden of data catch there is the adaptation of asynchronous and progressive refreshment strategy. To render data in $3 \mathrm{D}$ form on mobile $3 \mathrm{D}$ rendering is used. Implementation is done on the platform of PDA with the help of OPENGL ES 3D programming package and VC language [1].

\subsection{TIN-based vertex generation method}

This application focuses on the geographic information processing and visualization on mobile 3D and web 3D. Main motivation is on system architecture and prototype implementation for mobile and web 3D. For dynamic 3D terrain rendering system using high resolution satellite metaphors, some techniques and algorithms were applied and implemented by using graphic pipeline of OPENGL ES API. Those are TIN-based vertex generation with regular spacing elevation data for generating 3D terrain surface, image tiling for LOD, image-vertex texturing in order to resolve limited resource of mobile devices.

With the help of GML model and its schema components, users can describe the geographic types such as real or conceptual, which are used within their application domain. X3D supports 3D functions such as polygonal geometry, parametric geometry, hierarchical transformations, lighting, materials, multi-pass or multi-stage texture mapping, pixel and vertex shading, and hardware acceleration in [2]. 


\subsection{Interaction/ Interfacing:, event generator and frame decoder}

At client side mobile devices uses mobile 3D viewer application for the visualization. At client side to handle user interaction with mobile view there is use of interfacing and users occurrences are also handle at this side with the help of event generator. Frame decoder is also used to extract synchronies data, decode it and put it into visualization buffer. Frame buffer is also used to mange packet losses. This application also supports Gtk+ 1.2 and X11 graphics libraries under Linux [3].

With the help of 3D based user interface the room metaphor has been developed. Therefore the user can selects and identify devices based on position, orientation and form without having a technical knowledge. 3D user interface has so many advantages which allow the visualization of environment and its devices and create a direct correspondence between the physical objects and their 3D representations within the user interface. On a mobile device the Interaction Appliance (IA) runs this makes available the AMCO client and the user interface [6].

\subsection{Web Browser, 3D viewer}

At the client side of this application uses compact 3D viewer in JAVA and web browser to browse and rate 3D model. Viewer performs zooming function [5].

\subsection{Culling algorithm and RSSI (received signal strength indicator) algorithm}

Virtual Reality Modeling language is used for constructing 3D indoor building maps. 3D models are divided into two cells (rooms) and nodes (objects). These nodes are located in cell. To make a system more flexible and scalable, designer 2D map also been used.

Culling algorithm is implemented with the help of script presented in VRML. It developed three types of visibility cell to cell, cell to object and eye to object. When the VRML script is activated, cell is loaded where the user is present with the help of cell to cell visibility algorithm. When that cell is loaded only current cells objects are visible and at the end all the objects that are viewed by user are visible. Therefore in culling algorithm there is use of IsCellVisible and IsObjectVisible functions. Culling algorithm is more useful to minimize rendering time. With the help of RSSI smoothing algorithm distances are calculated between reference and blind objects. It also estimates user's location with the help of CC2431 location engine in 3D virtual reality environment. For the final experiment reference objects are located at each corners of ceiling in one cell for proper location tracking [7].

Mobile device like PDA are not allow large 3D model at acceptable frame rates due to their limitation. Therefore author proposed two culling algorithms i.e. hierarchical frustum culling and portal culling for interaction of large 3D model of building on mobile device. Large 3D model is subdivided into cells and portals having Meta data in X3D file [40].

\subsection{D rendering and navigation in virtual environment}

For the execution of ABMS (Agent Based Modeling Simulation) system author [8] design a client server architecture shown in fig.5 and also provides 3D rendering on wireless devices like mobiles, laptops etc.

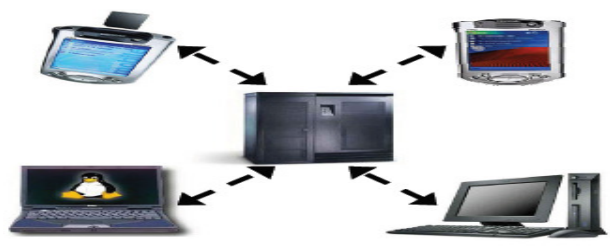

Fig. 5: ABMS rendering on different devices

3D visualizer at client side consist of three software components snapshot manager, virtual word creator and rendering engine. Snapshot Manager manages the succeeding activity of data 
decompression, and checks for their integrity. Virtual word creator takes data from queue and creates $3 \mathrm{D}$ virtual environment and the rendering engine perform $3 \mathrm{D}$ rendering of virtual environment on wireless devices.

Here authors $[14,18]$ provide system which provides 3D navigation on mobile.

Local 3D rendering is most probably done at client side to perform 3D visualization on mobile devices [27].

\subsection{Data compression and optimization technique}

Data compression also used at client side which is also called as software compression. Optimization of 3D virtual reality data is done by two way i.e. static and dynamic optimization. In static optimization conditions are not changed during execution. In case of static optimization data compression is either done by software or hardware to reduce data transmission rate. Hardware compression algorithm may use for software compression but it never change for different types of clients. In other case software compression algorithm may used for lower clients to use a lower compression rate as well as powerful devices for higher and more data compression. When clients wants to connect to server they have to infer to server about device capacity, processing power, sound resolution etc then server removes unwanted contents according to the client i.e. mobile device requirement.

In case of dynamic optimization, incremental data transmission is used which transfer only minimum needed data. Data processing is done at VRML proxy server side rather than client side. Content manipulation reduces the unwanted contents to mobile [9].

\subsection{Data Decompression}

Along with compression method decompression is also used at client side to decompress the compressed data which comes from server side. Data has been compress at server side to reduce the transmission rate of complex data. After decompression mobile users gets the view of whole data $[10,21,22,28]$.

\subsection{Zooming and rotation}

Zooming and rotation is performed at client side to navigate through $3 \mathrm{D}$ video $[11,28]$. Zooming technique is also used by visualizer of ABMS [8].

Tile images visualized at client side with the help of view operations like zoom, rotations etc. Client also supports multi threaded pull model for multiple tiles [12].

\subsection{D Multimedia Visualization with interactive navigation}

Multimedia objects are generated after survey of tourist information and preprocessing of remote sensing data. While preprocessing digital elevation model (DEM) is required for geocoding of remote sensing data and it is also important for 3D visualization. In the process of geo-coding, bi-cubic convolution re-sampling is useful to get an optimum visual representation. $3 \mathrm{D}$ views are calculated from the combination of RGB images and DEM and generally view in animation software. Multimedia objects can integrate with different applications on mobile [16].

\section{ANALYSIS OF VARIOUS TECHNIQUES CONSIDERING (APPLICATIONS, ATTRIBUTES, PAREMETERS AND THEIR ASPECTS)}


International Journal of Computer Science \& Information Technology (IJCSIT) Vol 3, No 6, Dec 2011

\begin{tabular}{|c|c|c|c|c|}
\hline Applications & Methods & Parameters & Related attributes & Aspects \\
\hline \multirow{6}{*}{$\begin{array}{l}\text { Geographic } \\
\text { data and earth } \\
\text { map 3D } \\
\text { visualization[ } \\
\text { 1] }\end{array}$} & $\begin{array}{l}\text { Roaming step } \\
\text { length control }\end{array}$ & Roaming step length & $\begin{array}{l}\text { Rotation degree, } \\
\text { Distance from earth, } \\
\text { Time of 3D } \\
\text { rendering }\end{array}$ & Rendering, \\
\hline & Motion blur & $\begin{array}{l}\text { Dynamic roaming, } \\
\text { 3D terrain mesh, } \\
\text { Geographic scene }\end{array}$ & $\begin{array}{l}\text { Small patches, } \\
\text { Reduces triangles }\end{array}$ & $\begin{array}{l}\text { 3D visualization, } \\
\text { Rendering }\end{array}$ \\
\hline & $\begin{array}{l}\text { Triangle } \\
\text { strips } \\
\text { division, }\end{array}$ & $\begin{array}{l}\text { Preprocess 3D } \\
\text { meshes, Divide 3D } \\
\text { meshes into triangle } \\
\text { strip }\end{array}$ & $\begin{array}{l}\text { Reduces 3D } \\
\text { rendering time }\end{array}$ & Rendering \\
\hline & $\begin{array}{l}\text { Data check } \\
\text { And } \\
\text { transmission }\end{array}$ & $\begin{array}{l}\text { Data updating } \\
\text { mechanism, } \\
\text { Correctness of data }\end{array}$ & $\begin{array}{l}\text { Spatial indexes, } \\
\text { Timestamp of } \\
\text { patches }\end{array}$ & $\begin{array}{l}\text { Wireless data } \\
\text { transmission }\end{array}$ \\
\hline & $\begin{array}{l}\text { Asynchronou } \\
\text { s refreshment }\end{array}$ & $\begin{array}{l}\text { Data scheduling, } \\
\text { Loading rough data } \\
\text { before accurate }\end{array}$ & $\begin{array}{l}\text { Release mobiles } \\
\text { data catch load, } \\
\text { Smooth roaming }\end{array}$ & $\begin{array}{l}\text { Data resolution, } \\
\text { Efficiency, } \\
\text { Speed, } \\
\text { Frequency, }\end{array}$ \\
\hline & $\begin{array}{l}\text { Dynamic } \\
\text { catching }\end{array}$ & $\begin{array}{l}\text { Data loading and } \\
\text { organization }\end{array}$ & $\begin{array}{l}\text { Represent Current } \\
\text { sense with inferior } \\
\text { data }\end{array}$ & $\begin{array}{l}\text { Speed and Space } \\
\text { limit, } \\
\text { 3D roaming }\end{array}$ \\
\hline $\begin{array}{l}\text { Terrain, } \\
\text { building, road } \\
\text { data } \\
\text { rendering [2] }\end{array}$ & $\begin{array}{l}\text { TIN based } \\
\text { vertex } \\
\text { generation }\end{array}$ & $\begin{array}{l}\text { Modeling, editing } \\
\text { and manipulating } \\
\text { 3D landscape } \\
\text { objects, optimizing } \\
\text { and rendering of } \\
\text { integrates 3D } \\
\text { landscape objects, } \\
\text { navigation of 3D } \\
\text { scene. }\end{array}$ & $\begin{array}{l}\text { Intuitive and user } \\
\text { friendly high } \\
\text { resolution remote } \\
\text { sense images }\end{array}$ & $\begin{array}{l}\text { Data transfer and } \\
\text { shearing of 3D urban } \\
\text { modeling }\end{array}$ \\
\hline \multirow[t]{2}{*}{$\begin{array}{l}\text { Complex } \\
\text { stream based } \\
\text { data like } \\
\text { video games } \\
\text { etc. } \\
\text { visualization } \\
{[3,4]}\end{array}$} & $\begin{array}{l}\text { Distributed } \\
\text { cluster based } \\
\text { rendering and } \\
\text { streaming } \\
\text { using } \\
\text { Chromium } \\
\text { framework } \\
\end{array}$ & $\begin{array}{l}\text { Event scheduler, } \\
\text { Streaming, } \\
\text { Rendering } \\
\text { Event generator, } \\
\text { Frame decoder }\end{array}$ & $\begin{array}{l}\text { Visualize interface } \\
\text { during OPENGL } \\
\text { API, } \\
\text { Run graphic } \\
\text { applications and } \\
\text { manages } \\
\text { communication } \\
\end{array}$ & $\begin{array}{l}\text { Fast network } \\
\text { connectivity, Frame } \\
\text { rates, screen } \\
\text { resolution, time, } \\
\text { stream quality, } \\
\text { network traffic }\end{array}$ \\
\hline & $\begin{array}{l}\text { Interaction/ } \\
\text { Interfacing/re } \\
\text { ndering }\end{array}$ & $\begin{array}{l}\text { Mobile interaction, } \\
\text { handles events } \\
\text { Render lines i.e. } \\
\text { Boundaries, } \\
\text { Ridges, } \\
\text { Valleys, Silhouettes }\end{array}$ & $\begin{array}{l}\text { Extract synchronize } \\
\text { bitstream, } \\
\text { handle packet loses, } \\
\text { decode compress } \\
\text { frames }\end{array}$ & $\begin{array}{l}\text { Bandwidth, } \\
\text { Reduce network } \\
\text { traffic, } \\
\text { Frame rates, } \\
\text { transmission time }\end{array}$ \\
\hline $\begin{array}{l}\text { 3D models } \\
\text { like vehicle } \\
\text { at remote } \\
\text { side[5] }\end{array}$ & $\begin{array}{l}\text { Interactive } \\
\text { generic } \\
\text { algorithm. }\end{array}$ & $\begin{array}{l}\text { Interactive 3D } \\
\text { modeling system } \\
\text { and mobile oriented } \\
\text { GUI, which } \\
\text { increases mobile } \\
\text { interactivity and } \\
\text { performance. }\end{array}$ & $\begin{array}{l}\text { Good quality mobile } \\
\text { 3D visualization } \\
\text { from anywhere } \\
\text { anytime. }\end{array}$ & $\begin{array}{l}\text { Frame Rate, } \\
\text { Image resolution. }\end{array}$ \\
\hline
\end{tabular}


International Journal of Computer Science \& Information Technology (IJCSIT) Vol 3, No 6, Dec 2011

\begin{tabular}{|c|c|c|c|c|}
\hline & Controller & $\begin{array}{l}\text { Manage client } \\
\text { server interaction, } \\
\text { converts 3D into 2D }\end{array}$ & $\begin{array}{l}\text { Transmission, } \\
\text { HTTP protocol }\end{array}$ & $\begin{array}{l}\text { Wireless } \\
\text { communication }\end{array}$ \\
\hline $\begin{array}{l}\text { To access } \\
\text { ambient } \\
\text { intelligent } \\
\text { environment }\end{array}$ & $\begin{array}{l}\text { Ambient } \\
\text { control and } \\
\text { The Dynamic } \\
\text { User } \\
\text { Interface } \\
\text { Creator[6] }\end{array}$ & $\begin{array}{l}\text { Dynamic 3D visua- } \\
\text { lization, user } \\
\text { interface creation, } \\
\text { and context } \\
\text { retrieval, interaction } \\
\text { synchronization etc. }\end{array}$ & $\begin{array}{l}\text { Controllability, } \\
\text { Document and } \\
\text { device access is } \\
\text { integrated in same } \\
\text { user interface. }\end{array}$ & $\begin{array}{l}\text { Error tolerance, } \\
\text { Efficiency, } \\
\text { Gateways, } \\
\text { Sensor tube. }\end{array}$ \\
\hline $\begin{array}{l}\text { Indoor } \\
\text { environment } \\
\text { GPS tracking } \\
\text { system }\end{array}$ & $\begin{array}{l}\text { Culling } \\
\text { algorithm and } \\
\text { RSSI } \\
\text { (received } \\
\text { signal } \\
\text { strength } \\
\text { indicator) } \\
\text { algorithm[7]: }\end{array}$ & $\begin{array}{l}\text { Reduce 3D } \\
\text { rendering time, } \\
\text { decrease comput- } \\
\text { ing time on mobile } \\
\text { devices, and } \\
\text { increase the system } \\
\text { performance. }\end{array}$ & $\begin{array}{l}\text { Accurate real time } \\
\text { rendering in indoor } \\
\text { environment, 3D } \\
\text { rendering, distance } \\
\text { and position } \\
\text { estimation. }\end{array}$ & $\begin{array}{l}\text { Location tracking } \\
\text { with 3D view, } \\
\text { Increase flexibility } \\
\text { and scalability using } \\
\text { 2D view. }\end{array}$ \\
\hline \multirow[t]{2}{*}{$\begin{array}{l}\text { Agent based } \\
\text { multimedia } \\
\text { simulation in } \\
\text { virtual } \\
\text { environment [ } \\
\text { 8] }\end{array}$} & $\begin{array}{l}\text { Agent Based } \\
\text { Modeling } \\
\text { Simulation } \\
\text { (ABMS) } \\
\text { Technology }\end{array}$ & $\begin{array}{l}\text { Fast 3D } \\
\text { visualization using } \\
\text { visual engine on } \\
\text { wireless devices, } \\
\text { perfect } \\
\text { synchronization } \\
\text { between client and } \\
\text { server.. }\end{array}$ & $\begin{array}{l}\text { Scientific } \\
\text { visualization on } \\
\text { mobile in virtual } \\
\text { world using } \\
\text { simulator, } \\
\text { reproduction, } \\
\text { compatibility. }\end{array}$ & $\begin{array}{l}\text { Wireless network } \\
\text { communication, } \\
\text { dynamic rendering, } \\
\text { Catching, } \\
\text { Fetching }\end{array}$ \\
\hline & Zooming & $\begin{array}{l}\text { Visualize large } \\
\text { image on small } \\
\text { display }\end{array}$ & Visualizer & Dynamic rendering \\
\hline \multirow[t]{2}{*}{$\begin{array}{l}\text { To view 3D } \\
\text { virtual reality } \\
\text { data, city } \\
\text { map, medical } \\
\text { data etc[9, 14, } \\
18,21,22, \\
25,26,27]\end{array}$} & $\begin{array}{l}\text { Data } \\
\text { compression } \\
\text { algorithm }\end{array}$ & $\begin{array}{l}\text { Requires minimum } \\
\text { computation and } \\
\text { memory resources at } \\
\text { client, } \\
\text { Reduces the } \\
\text { download time and } \\
\text { control the flow of } \\
\text { 3D data }\end{array}$ & $\begin{array}{l}\text { Visualization of } \\
\text { complex data on } \\
\text { mobile device in } \\
\text { distributed } \\
\text { environment. } \\
\text { Low compression } \\
\text { rate for slow } \\
\text { mobiles and high } \\
\text { compression for } \\
\text { powerful mobiles }\end{array}$ & $\begin{array}{l}\text { Data transmission } \\
\text { rate, } \\
\text { Compression quality, } \\
\text { Bandwidth. }\end{array}$ \\
\hline & $\begin{array}{l}\text { Dynamic } \\
\text { optimization } \\
\text { technique }\end{array}$ & $\begin{array}{l}\text { Manage dynamic } \\
\text { entity, provide } \\
\text { dynamic view, } \\
\text { better performance, } \\
\text { and image quality, } \\
\text { reduce fetch time, } \\
\text { satisfy users with } \\
\text { quality of } \\
\text { experience, and } \\
\text { provide flexible } \\
\text { interaction in grid } \\
\text { environment. }\end{array}$ & $\begin{array}{l}\text { Improve data } \\
\text { transmission on } \\
\text { wireless network }\end{array}$ & $\begin{array}{l}\text { Wireless network, } \\
\text { GPS, } \\
\text { Packed pixel array, } \\
\text { Ray tracing, } \\
\text { Caching and pre- } \\
\text { Fetching, } \\
\text { Frame rates, } \\
\text { Image resolution, } \\
\text { Bandwidth }\end{array}$ \\
\hline $\begin{array}{l}\text { 3D } \\
\text { visualization } \\
\text { of large } \\
\text { cities. } \\
\text { Moving } \\
\text { location } \\
\text { query as } \\
\end{array}$ & $\begin{array}{l}\text { Non- } \\
\text { photorealistic } \\
\text { rendering } \\
(\mathrm{NPR})\end{array}$ & $\begin{array}{l}\text { Fast line based and } \\
\text { high quality } \\
\text { rendering, Server } \\
\text { load reduction and } \\
\text { communication, } \\
\text { Feature line } \\
\text { extraction from }\end{array}$ & $\begin{array}{l}\text { Location watching } \\
\text { on mobile in } \\
\text { distributed } \\
\text { surrounding, } \\
\text { Gradient magnitude } \\
\text { and direction. } \\
\text { Poly line and graph }\end{array}$ & $\begin{array}{l}\text { Wireless } \\
\text { communication, } \\
\text { Edge detection, } \\
\text { Segment suppression, } \\
\text { Pixel chaining, } \\
\text { Loading, } \\
\text { Pre-fetching, }\end{array}$ \\
\hline
\end{tabular}


International Journal of Computer Science \& Information Technology (IJCSIT) Vol 3, No 6, Dec 2011

\begin{tabular}{|c|c|c|c|c|}
\hline \multirow{2}{*}{$\begin{array}{l}\text { location } \\
\text { tracking and } \\
\text { monitoring } \\
{[10,19]}\end{array}$} & & image front & $\begin{array}{l}\text { structure., filtering, } \\
\text { threshold }\end{array}$ & \\
\hline & $\begin{array}{l}\text { Preprocessing } \\
\text { optimization } \\
\text { technique }\end{array}$ & $\begin{array}{l}\text { Fast rendering, } \\
\text { Reduce processing } \\
\text { load at mobile, filter }\end{array}$ & $\begin{array}{l}\text { focal object, spatial } \\
\text { queries, reserve } \\
\text { query index matrix, } \\
\text { static grid cell }\end{array}$ & $\begin{array}{l}\text { Wireless } \\
\text { communication, } \\
\text { Bandwidth }\end{array}$ \\
\hline $\begin{array}{l}\text { Real time } \\
\text { remote } \\
\text { rendering of } \\
\text { 3D video }\end{array}$ & $\begin{array}{l}\text { Image based } \\
\text { approach } \\
\text { with 3D } \\
\text { wrapping, } \\
\text { Zooming and } \\
\text { rotation [11] }\end{array}$ & $\begin{array}{l}\text { Proxy based } \\
\text { structure, } \\
\text { Visualization of } \\
\text { whole 3D video } \\
\text { frame on mobile. } \\
\text { Dynamic, real time } \\
\text { and temporary } \\
\text { frame rendering. }\end{array}$ & $\begin{array}{l}\text { High quality 3D } \\
\text { visualization, 3D } \\
\text { video stream, } \\
\text { gateway server, less } \\
\text { computation } \\
\text { resources, } \\
\text { processing time }\end{array}$ & $\begin{array}{l}\text { Network traffic, } \\
\text { Interaction delay, } \\
\text { Image resolution, } \\
\text { Pixel depth, } \\
\text { Rendering } \\
\text { performance and } \\
\text { quality, } \\
\text { Bandwidth }\end{array}$ \\
\hline $\begin{array}{l}\text { Visualization } \\
\text { of image } \\
\text { data. }\end{array}$ & $\begin{array}{l}\text { Image } \\
\text { Tilling, } \\
\text { Multi- } \\
\text { resolution } \\
\text { Streaming, } \\
\text { Zooming and } \\
\text { rotation [12]: }\end{array}$ & $\begin{array}{l}\text { Interactive } \\
\text { visualization on } \\
\text { mobile, encoder, } \\
\text { Multi threaded pull } \\
\text { model }\end{array}$ & $\begin{array}{l}\text { Interactive } \\
\text { visualization using } \\
\text { structure, multi- } \\
\text { resolution images, } \\
\text { tile images, } \\
\text { preprocess image. }\end{array}$ & $\begin{array}{l}\text { Internet delivery, } \\
\text { Multi-resolution, } \\
\text { Streaming, } \\
\text { Decoder }\end{array}$ \\
\hline $\begin{array}{l}\text { Graphical } \\
\text { user } \\
\text { interfacing on } \\
\text { mobile }\end{array}$ & $\begin{array}{l}\text { GUI with } \\
\text { Segmentation } \\
\text {, Optical } \\
\text { character } \\
\text { recognition } \\
\text { and Pattern } \\
\text { matching } \\
\text { techniques[13 } \\
\text { ] }\end{array}$ & $\begin{array}{l}\text { Client server } \\
\text { framework, image } \\
\text { segmentation, } \\
\text { parser, classifier, } \\
\text { descriptor. }\end{array}$ & $\begin{array}{l}\text { Control the remote } \\
\text { requests using } \\
\text { GUI., interfacing, } \\
\text { categorize elements } \\
\text { to put together, } \\
\text { convert information } \\
\text { into user interface } \\
\text {,image sub blokes, } \\
\text { character shapes, } \\
\text { bounding box }\end{array}$ & $\begin{array}{l}\text { Frame buffer, } \\
\text { Ad hoc network }\end{array}$ \\
\hline $\begin{array}{l}\text { Location } \\
\text { finding of } \\
\text { indoor } \\
\text { environment } \\
\text { and navigate. }\end{array}$ & $\begin{array}{l}\text { Image } \\
\text { Segmentation } \\
\text { and Matching } \\
\text { technique. } \\
{[15,18]}\end{array}$ & $\begin{array}{l}\text { Visualization and } \\
\text { navigation of indoor } \\
\text { environment on } \\
\text { mobile, feature } \\
\text { extraction and } \\
\text { detection }\end{array}$ & $\begin{array}{l}\text { Shows position and } \\
\text { direction in indoor } \\
\text { environment., find } \\
\text { segment, line trace, } \\
\text { floor plan }\end{array}$ & Wireless signals, \\
\hline $\begin{array}{l}\text { Visualization } \\
\text { of complex } \\
\text { virtual 3D } \\
\text { scenes and } \\
\text { navigate them } \\
\text { on mobile } \\
\text { devices }\end{array}$ & $\begin{array}{l}\text { Multi- } \\
\text { resolution, } \\
\text { view frustum } \\
\text { culling, } \\
\text { occlusion } \\
\text { culling, } \\
\text { imposter } \\
\text { techniques, } \\
\text { and scene- } \\
\text { graph } \\
\text { optimizations } \\
:[20] \\
\end{array}$ & $\begin{array}{l}\text { Provides web } \\
\text { service interfacing, } \\
\text { improve the } \\
\text { rendering speed of } \\
\text { 3D navigation, } \\
\text { efficient network } \\
\text { transmission. } \\
\text { Pyramid with } \\
\text { hierarchical quad } \\
\text { tree, latitude, } \\
\text { longitude }\end{array}$ & $\begin{array}{l}\text { Server generates } \\
\text { dynamic } 3 \mathrm{D} \text { view } \\
\text { and then send } \\
\text { encoded image to } \\
\text { mobile client, define } \\
\text { data structure, } \\
\text { compress spatial } \\
\text { data, reduce data } \\
\text { redundancy. }\end{array}$ & $\begin{array}{l}\text { GPS location, } \\
\text { Video encoder, } \\
\text { Network } \\
\text { transmission, Frame } \\
\text { rates, }\end{array}$ \\
\hline $\begin{array}{l}\text { Rendering of } \\
\text { complex 3D } \\
\text { image data on } \\
\text { mobile which } \\
\text { flows from } \\
\text { server, } \\
\text { interactive }\end{array}$ & $\begin{array}{l}\text { Adoptive and } \\
\text { model view } \\
\text { Control }\end{array}$ & $\begin{array}{l}\text { Decrease bandwidth } \\
\text { between client and } \\
\text { server, } \\
\text { increase mobile } \\
\text { throughputs, } \\
\text { Maintain image } \\
\text { quality and }\end{array}$ & $\begin{array}{l}\text { Flow of interactive } \\
\text { multimedia over } \\
\text { wireless network } \\
\text { using controller. } \\
\text { High quality 3D } \\
\text { visualization. } \\
\text { Enhance motion }\end{array}$ & $\begin{array}{l}\text { Wireless network, } \\
\text { Bandwidth, } \\
\text { Throughputs, } \\
\text { Frame rates. } \\
\text { Fault tolerant, } \\
\text { Ad hoc network, } \\
\text { Data communication }\end{array}$ \\
\hline
\end{tabular}


International Journal of Computer Science \& Information Technology (IJCSIT) Vol 3, No 6, Dec 2011

\begin{tabular}{|c|c|c|c|c|}
\hline $\begin{array}{l}\text { visualization } \\
\text { of multimedia } \\
\text { data and } \\
\text { navigation of } \\
\text { 3D view of } \\
\text { museum } \\
\text { applications. }\end{array}$ & $\begin{array}{l}\text { System: } \\
{[23,24]}\end{array}$ & $\begin{array}{l}\text { resolution. } \\
\text { QoS. } \\
\text { Performs navigation } \\
\text { and interaction in } \\
\text { between multiple } \\
\text { mobile clients, } \\
\text { Model view } \\
\text { controller }\end{array}$ & $\begin{array}{l}\text { smoothness, Impact } \\
\text { on interactivity, } \\
\text { Target frame rates } \\
\text { maintain resolution } \\
\text { and quality } \\
\text { Manage } 3 \mathrm{~d} \text { graphics, } \\
\text { Response to } \\
\text { potential geographic } \\
\text { collision }\end{array}$ & \\
\hline $\begin{array}{l}\text { Medical data } \\
\text { visualization } \\
\text { in grid } \\
\text { environment }\end{array}$ & $\begin{array}{l}\text { Volume and } \\
\text { Iso-surface } \\
\text { rendering } \\
\text { methods:[27] }\end{array}$ & $\begin{array}{l}\text { Converts data into } \\
\text { geometric form } \\
\text { which is then render } \\
\text { into, large data flow } \\
\text { and steering }\end{array}$ & $\begin{array}{l}\text { Interactive } \\
\text { Visualization and } \\
\text { precise controlling } \\
\text { of large datasets on } \\
\text { mobile }\end{array}$ & $\begin{array}{l}\text { Network bandwidth, } \\
\text { Image streaming. }\end{array}$ \\
\hline $\begin{array}{l}\text { Real time } \\
\text { multidimensi } \\
\text { onal data }\end{array}$ & $\begin{array}{l}\text { Compression, } \\
\text { decompressio } \\
\mathrm{n}[28]\end{array}$ & $\begin{array}{l}\text { Image stream, } \\
\text { remote } \\
\text { visualization, } \\
\text { distributed network. }\end{array}$ & $\begin{array}{l}\text { Increase image } \\
\text { quality, high frame } \\
\text { rates, decrease } \\
\text { network latency }\end{array}$ & $\begin{array}{l}\text { Broadband } \\
\text { connection, Screen } \\
\text { and image resolution }\end{array}$ \\
\hline
\end{tabular}

\section{RESULTS AND DISCUSSION}

From the above analysis it has been found that most of the techniques are use at server side for remote visualization on mobile devices.

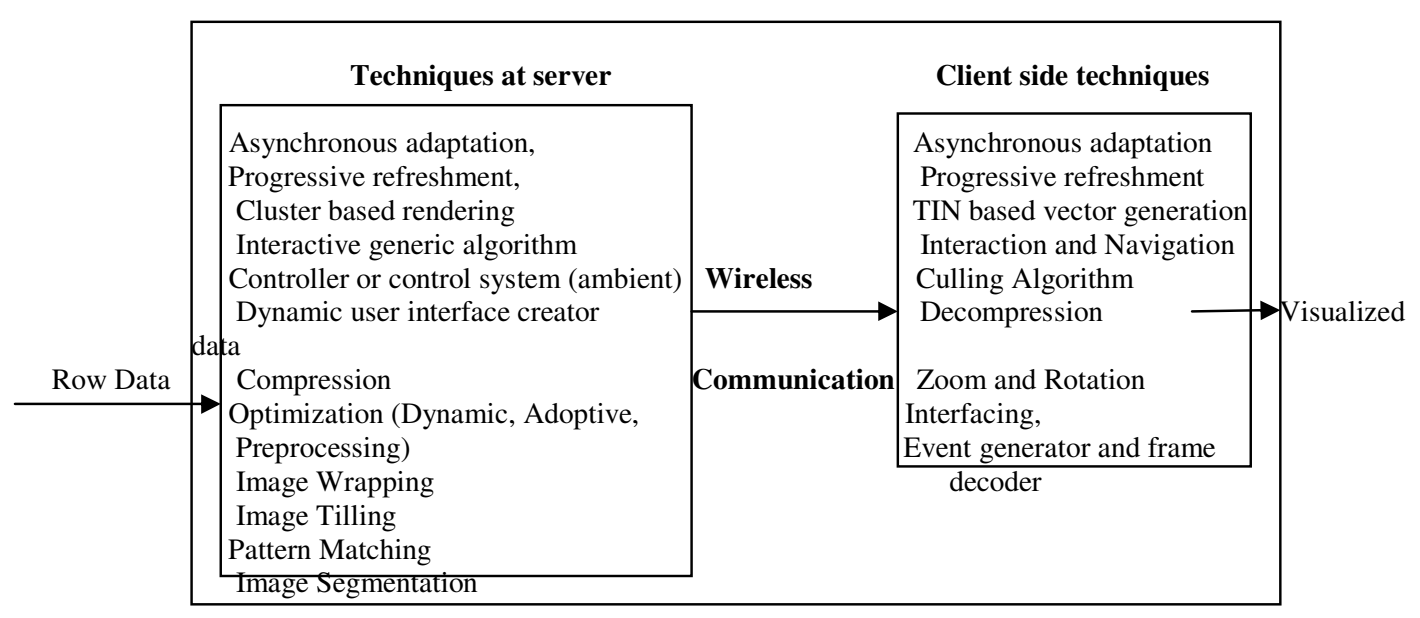

Fig 6: Framework of most probable techniques used at server side and client side

To make 3D visualization of complex data more effective on mobile devices there is use of remote visualization. Actually various reasons are found which build remote visualization on mobile devices more successful.

1. As the data transfer through wireless network therefore when the client requests for new rendering then interaction delay may occur due to network traffic. This interaction delay is reduced with the help of image based approach. Image based approach uses 3D wrapping technique to reduce interaction delay

2. Continuous data catching is not possible due to limited storage capacity of mobile devices this is overcomes by adaptation of asynchronous, progressive refreshment strategy and data compression techniques. 
International Journal of Computer Science \& Information Technology (IJCSIT) Vol 3, No 6, Dec 2011

3. Visualization of environment and its devices and create a direct correspondence between the physical objects and their 3D representations within the user interface.

4. As the wireless connection via wireless network is not more reliable due to their limited bandwidth therefore 3D virtual reality has been optimized before going towards wireless network.

5. In case of client server approach render data has been store on server such data then optimize for remote visualization on client like mobile device, PDA etc. Optimization technique has been used due to the fewer configurations of clients.

6. With the help of different techniques such as roaming step length control, motion blur, and triangle strips division it is possible to improve the efficiency of $3 \mathrm{D}$ rendering on the intelligent mobile devices via wireless data transmission.

\section{Conclusions}

Here the concentration is on different techniques those are responsible for visualization on mobile devices at remote side from server. Most of the techniques are useful for server to send data for visualization to mobile devices. It has been found that optimization and compression methods are more useful for the remote visualization. Also discuss the various advantages of remote visualization on mobile devices.

In this paper discussion is on different techniques in various applications their attributes, parameters and aspects. Remote visualization on mobile devices considers various aspects such wireless connectivity, bandwidth, frame rates, throughputs, fault tolerant, cache, fetch, interaction delay, resolution etc. in different applications with different techniques.

\section{REFERENCES}

[1] X. Sun, QingW. Hu, HuaY. Wu (2009), "Design and Implementation of Global 3D Visualization Client Program on Intelligent Mobile Devices", Third International Conference on Multimedia and Ubiquitous Engineering, Qingdao, pp 459 - 464, ISBN: 978-0-7695-3658-3.

[2] Kiwon Lee (2007), "3D Urban Modeling and Rendering with High Resolution Remote Sensing Imagery on Mobile 3D and Web 3D Environments", Urban Remote Sensing Joint Event, Paris, ISBN: 1-4244-0712-5, pp $1-5$.

[3] Fabrizio Lamberti, Andrea Sanna (2007), "A Streaming-Based Solution for Remote Visualization of 3D Graphics on Mobile Devices.", IEEE Transactions On Visualization And Computer Graphics, Vol. 13, No. 2, pp 247-260.

[4] Joachim Diepstraten, Martin Gorke, Thomas Ertl, (2004), "Remote Line Rendering for Mobile Devices", IEEE Proceedings of the Computer Graphics International.

[5] Hiroaki Nishino, Tsuneo Kagawa, Kouichi Utsumiya, (2009) "A Mobile Graphics System for Ubiquitous Environment”, International Conference on Network-Based Information Systems, USA, ISBN: 978-0-7695-3767-2 pp 83-90.

[6] Ali Asghar Nazari Shirehjini, Shervin Shirmohammadi, (2009), "A Mobile 3D User Interface for Interaction with Ambient Audio Visual Environments", IEEE International Workshop on Haptic Audio visual Environments and Games, Lecco, ISBN: 978-1-4244-4217-1, pp186 - 191.

[7] Boon-Giin Lee, Young-Sook Lee, Wan-Young Chung, (2008), "3D Map Visualization for Real Time RSSI Indoor Location Tracking System on PDA", Proceeding of third international conference on Convergence and Hybrid Information Technology, Busan, ISBN 978-0-7695-34077, pp 375-381.

[8] S. Cacciaguerra, M. Roccetti, M. Roffilli, A. Lomi, (2004), "A Wireless Software Architecture for Fast 3D Rendering of Agent-Based Multimedia Simulations on Portable Devices", First IEEE Conference on Consumer Communications and Networking, ISBN: 0-7803-8145-9, pp 589 - 594. 
International Journal of Computer Science \& Information Technology (IJCSIT) Vol 3, No 6, Dec 2011

[9] Markus Feibt, Andreas Christ, (2004) "Dynamically optimized 3D (virtual reality) data transmission for mobile devices", Proceedings of the 2nd International Symposium on 3D Data Processing, Visualization, and Transmission, IEEE Computer Society, ISBN: 0-7695-2223-8.

[10] Jean-Charles Quillet, Gwenola Thomas, Xavier Granier, Pascal Guitton, Jean-Eudes Marvie, (2006), "Using Expressive Rendering for Remote Visualization of Large City Models", Proceedings of the eleventh international conference on $3 D$ web technology, ACM, New York, USA, ISBN: 1-59593-336-0, pp 27 - 35.

[11] Shu Shi, Won J. Jeon, Klara Nahrstedt, and Roy H. Campbell, (2009), "Real-Time Remote Rendering of 3D Video for Mobile Devices", Proceedings of the seventeen ACM international conference on Multimedia, China, pp- 391-400.

[12] Jerry Chen, Limi Yoon, E. Wes Bethel, (2008), "Interactive, Internet Delivery of Visualization Via Structure Prerendered Multiresolution Imagery", IEEE Transaction on Visualization And Computer Graphics, Vol. 14, No. 2, pp 302-312.

[13] Fabrizio Lamberty and Andrea Sanna, (2008), "Extensible GUI for Remote Application Control on Mobile Devices", Published by IEEE Computer Society, pp 50-57.

[14] Antti Nurminen, (2008), “Mobile 3D City Maps”, Published by IEEE Computer Society, pp 2031.

[15] Harlan Hile and Gaetano Borriello, (2008), "Positioning and Orientation in Indoor Environment Using Camera Phone”, Published by IEEE Computer Society, pp 32-39.

[16]Alexander Almer, Harald Stelzl, (2002), "Multimedia Visualization of Geo-information for Tourisms Region Based on Remote sensing Data", Symposium on Geospatial Theory, Processing and Applications, Ottawa.

[17] Dr. A. Sanna, Dr. G. Paravati, Dr. E. Godio, Dr. D. Fiorella, (2008), "Visualization of 3D complex scenes on mobile devices", Information Society Technologies Program, pp 1-28.

[18] Kari Pulli, Scott Klemmer, (2008), “Mobile Graphics”, Published by IEEE Computer Society, pp 18-19.

[19] Bugra Gedik, Ling Liu, (2006), "MobiEyes: A Distributed Location Monitoring Service Using Moving Location Queries" , IEEE Transaction on Mobile Computing, Vol. 5 No. 10, pp 13841402.

[20] Wen Jiang, Wu Yuguo, Wang Fan, (2009), “ An Approach For Navigation In 3d Models On Mobile Devices", In: Stilla U, Rottensteiner F, Paparoditis $N$ (Eds) CMRT09. IAPRS, Vol. XXXVIII, Part 3/W4, Paris, France, pp 109-114.

[21]Pietro Zanuttigh, Giampaolo Michieletto, Guido Maria Cortelazzo, (2005), “A Predictive Compression Method For Remote Visualization Of 3d Models", In Proceedings of International Workshop VLBV05, (Cagliari, Italy).

[22] Matt Aranha, Piotr Dubla, Kurt Debattista, Thomas Bashford-Rogers, (2007), Alan Chalmers, "A Physically-Based Client-Server Rendering Solution For Mobile Devices", Proceeding of the $6^{\text {th }}$ international conference on mobile and ubiquitous multimedia, ACM, New York, USA ISBN 9781-59593-916-6, pp 149-154.

[23] Gianluca Paravati ,Andrea Sanna ,Fabrizio Lamberti , Luigi Ciminiera, (2010), “An Adaptive Control System to Deliver Interactive Virtual Environment Content to Handheld Devices", Springer Science+Business Media, Mobile Netw Appl, pp 385-393.

[24] Maria Andréia F. Rodrigues, Rafael G. Barbosa, Nabor C. Mendonça, (2006), "Interactive Mobile 3D Graphics for On-the-go Visualization and Walkthroughs", Proceeding of the ACM symposium on Applied Computing, New York, USA, ISBN:1-59593-108-2.

[25] Robert Sisneros, Chad Jones, Jian Huang, Jinzhu Gao, Byung-Hoon Park, And Nagiza F. Samatova, (2007), "A Multilevel Cache Model For Runtime Optimization Of Remote Visualization”, IEEE Transactions On Visualization And Computer Graphics, Vol. 13, No. 5, pp $1-13$. 
International Journal of Computer Science \& Information Technology (IJCSIT) Vol 3, No 6, Dec 2011

[26] Gianluca Paravati, Andrea Sanna, Fabrizio Lamberti, Luigi Ciminiera, (2010), "On Quality of experience in remote Visualization on Mobile devices", International Journal of Mobile Human Computer Interaction, 2(1), pp 1-20.

[27] Aboamama .A. Ahmed, Muhammad .S Abd Latiff, Kamalrulnizam Abu Bakar, (2006), "Remote Visualization on Medical Datasets over Thin Clients with Support of Grid Environment", Proceedings of the Postgraduate Annual Research Seminar, UTM Skudai pp 133-137.

[28] M. Panka, M. Chlebiej, K. Benedyczak and P. Bala, (2011), "Visualization of Multidimensional Data on distributed mobile devices using interactive video streaming techniques", Proceedings of the 34th International Convention, MIPRO, Opatija, Croatia, ISBN: 978-1-4577-0996-8, pp 246251.

[29] Mengxia Zhu, Qishi Wu, Nageswara S. V. Rao, S. Sitharama Iyengar, (2004), "Adaptive Visualization Pipeline Decomposition and Mapping onto Computer Network", 3rd International Conference on Image and Graphics, Hong Kong, China.

[30] Mengxia Zhu, QishiWu, Nageswara S.V. Rao, Sitharama Iyengar, (2007), "Optimal pipeline decomposition and adaptive network mapping to support distributed remote visualization", $J$. Parallel Distrib. Comput. Vol. 67 pp-947 - 956.

[31] Pietro Zanuttigh, Nicola Brusco, David Taubman, Guido Cortelazzo, (2006), "A novel framework for the interactive transmission of 3D scenes”, Signal Processing: Image Communication, Vol. 21 pp- 787-811.

[32] Pietro Zanuttigh, "A Rate-Distortion Framework for Transmission and Remote Visualization of 3D Models", Phd Thesis, http://ittm.dei.unipd.it/nuovo/papers/phdzanuttigh .

[33] Paravati G, Sanna A, Lamberti F, Ciminiera L (2008) "A novel approach to support quality of experience in remote visualization on mobile devices", In: Eurographics short paper proceedings, pp 223-226.

[34]Zhigang Hua, Xing Xie, Hao Liu, Hanqing Lu, Wei-Ying Ma, (2006), "Design and performance study of an adoptive scheme for serving dynamic web content in a mobile computing environment”, IEEE Transactions On Mobile Computing, Vol. 5, No. 12, pp 1650-1662.

[35] Constantinos Papadopoulos, (2006), "Improve awareness in mobile CSCW", IEEE Transactions on Mobile Computing, Vol.5, No. 10, pp 1331 - 1346.

[36] Sylvain Faisan, Nicolas Passat, Vincent Noblet, Renée Chabrier, and Christophe Meyer, (2011), "Topology Preserving Warping of 3-D Binary Images According to Continuous One-to-One Mappings", IEEE Transactions On Image Processing, Vol. 20, No. 8, pp 2135-2145.

[37] Pradeep Sen, Soheil Darabi, (2011), "Compressive Rendering: A Rendering Application of Compressed Sensing”. IEEE Transactions on Visualization and Computer Graphics, Vol. 17, No. 4, pp 487-499.

[38] Pietro Zanuttigh, Guido M. Cortelazzo, "Compression Of Depth Information For 3D Rendering”, http://ittm.dei.unipd.it/nuovo/papers/3dtv09.pdf

[39] Milos Bogdanovic, Danilo Vulovic, Leonid Stoimenov, (2011), “,Web Map Context Service for Adaptive Geospatial Data Visualization", AGILE.

[40] Alessandro Mulloni, Daniele Nadalutti, Luca Chittaro, (2007), "Interactive Walkthrough of Large 3D Models of Buildings on Mobile Devices", Proceeding of twelfth international conference on Web3D technology, Italy, Vol.1, ACM 978-1-59593-652-3. 
Authors

Short Biography

Ujwala Junghare received the degree of M.Sc. in computer science in 2003 from SGB Amravati University, Amravati. Also receive M.Phil degree in 2009 from YCMOU. Presently working as Asst. Coordinator in the Department of Computer Science and having 7 years of teaching experience. Her area of research is Visualization, Mobile Computing and doing her Ph.D. in 3D Visualization on Mobile Devices. Number of papers on her credits at National \& International level journals and conferences.

Dr. V.M. Thakare is working as Professor \& Head in Computer Science from last 9 years, Faculty of Engineering \& Technology, Post Graduate Department of Computer Science, SGB Amravati University, Amravati. He has published 86 papers in various National \& International Conferences \& 20 papers in various International journals. $\mathrm{He}$ is working on various bodies of Universities as a chairman \& members. He has guided around 300 more students at M.E / MTech, MCA M.S \& M.Phil level. He is a research guide for Ph.D. at S.G.B. Amravati University, Amravati. His interest of

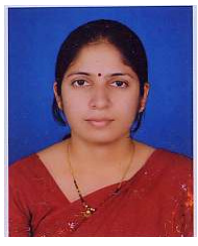
research is in Computer Architecture, Artificial Intelligence and Robotics, Database and Data warehousing \& mining.

Dr. Rajiv V. Dharaskar is working as Director, M.P.G.I. Nanded, MS. India. He is Ph.D. in Computer Science \& Engineering in the Faculty of Engineering \& Technology, M.Tech. (Computers), P.G. Dip., M.Phil., and M.Sc. He is having 25 years of teaching and 18 years of $R \& D$ experience in the field of Computers \& IT Professor has authored or co-authored number of books on Programming Languages and over 150 research papers on computer engineering. He has been actively involved in the research on Software Engineering, Mobile Computing, Multimedia,

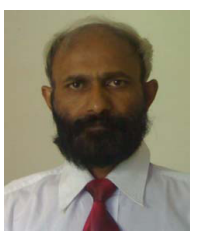
Web Technology, HCI, E-Commerce, E-Learning etc. He has delivered numerous Keynote addresses at national and international computer.

Dr. Swati Sherekar received the degree of M.Sc. in computer science in 1994 from SGB Amravati University, Amravati. Presently working as Associate Professor in the P. G. Department of Computer Science and having 16 years of teaching experience. Her area of research is Multimedia security, Image Processing and completed her Ph.D in 2011, in Digital Watermarking for multimedia authentication. Completed one MRP. Number of papers on her credits at National \& International level journals and conferences.

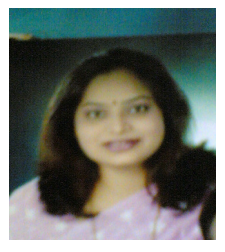

